\title{
Re-thinking Urban Planning for Singapore's Extended Lifespan Population of 2050: A League of its Own
}

\author{
André Siew Yeong Yew \\ (i) https://orcid.org/0000-0002-0052-7457 \\ James Cook University, Singapore
}

\begin{abstract}
The United Nations Sustainable Development Goals and the World Health Organization's Healthy Aging and Age Friendly Environment are comprehensive guidelines in ascertaining global standards for betterment of aging populations. However, as an economically established and highly organised city-state, Singapore has its own separate set of criteria regarding successful aging. This paper explores the contexts of living, working, and playing in Singapore's current 65 and over population and the population over the age of 65 by 2050 . The study demonstrates that these elderly life contexts are not only dissimilar to those on which the UN and WHO guidelines are based, but are uniquely Singaporean. These life, work and play contexts of an aging population also generate a new set of criteria that impact the model in urban planning and design for the tropical island-state. In this paper I argue that Singapore's current 65 and over population is not the typical aging population, but one characterised by an extended lifespan with autonomy, employability, and vitality. These characteristics will be even more prominent for the country's over the age of 65 by 2050 population, which will be comprised of the current Gen X and Millennials. To maintain sustainability and adaptability, urbanisation strategies in Singapore need to take into consideration these different generations of an aging population, which necessitate that planning and design recognise sets of criteria unique to each generation.
\end{abstract}

Keywords: healthy aging, urban planning, Singapore, tropical urbanism

eTropic: electronic journal of studies in the tropics publishes new research from arts, humanities, social sciences and allied fields on the variety and interrelatedness of nature, culture, and society in the tropics. Published by James Cook University, a leading research institution on critical issues facing the worlds' Tropics. Free open access, Scopus Listed, Scimago Q2. Indexed in: Google Scholar, DOAJ, Crossref, Ulrich's, SHERPA/RoMEO, Pandora. ISSN 1448-2940. Creative Commons CC BY 4.0 free to download, save and reproduce. To cite, include: Author(s), Title, eTropic, volume, issue, year, pages and DOI: http://dx.doi.org/10.25120/etropic.19.2.2020.3744 
eTropic 19.2 (2020) Special Issue: Sustainable Tropical Urbanism

\section{$\mathrm{T}$} he United Nations Sustainable Development Goals and the World Health Organization Healthy Aging and Age Friendly Environment guidelines included in the Global Strategy and Action Plan on Aging and Health are initiatives that address global aging population issues (WHO, 2017). Together they form the basis for urban planning, policy, and strategy development for healthy elderly lifestyle environments. This paper hypothesises that the global initiatives are insufficient to address Singapore's current 65 and over population, and will be inapplicable to the country's emerging over 65 by 2050 population. The background context of the UN and WHO guidelines is broad and does not identify with the living, working and playing environments of the highly educated population of Singapore who live healthier, more active, and longer lives within a structured and safe high-density urban environment. Singapore's dynamic social morphology demands tailored urban planning criteria for healthy aging.

This paper firstly undertakes an analysis of the trends in life, work and play lifestyles of Singapore's current 65 and over population (made up of the post-colonial babyboomer generation born between 1947-1964 or before) and the emerging over 65 by 2050 population (the generation currently between 25-35 years old which comprises Gen X and Millennials with baby-boomer parents). The analysis of lifestyle trends is based on the evolving socio-economic environment of Singapore's current 65 and over and the emerging 65 by 2050 populations inferred from secondary data of Singapore's current population statistics, public housing demands, workforce development and consumer behaviours. This data is used to interpret and extrapolate upon the Singapore context for living, working, and playing in the aging population.

This preliminary analysis attempts to identify the evolving population-specific living contexts from which an extrapolating set of urban planning and design baseline criteria respective to the population follows. The objectives are to establish the nonapplicability of the UN and WHO initiatives for Singapore's aging population, and to demonstrate the need for an alternative contemplation in urban planning based on social morphology for a society in accelerated transformation. This set of criteria will be used in the subsequent comparison against the UN and WHO initiatives. The analysis and comparative study demonstrate that the Singapore aging population is not a morbid one, but comprises an active population with extended lifespan.

Research on Singapore's aging population is diverse, ranging from optimism in developing better urban settings for social interaction in active aging (Aw, et al., 2017) and a smarter eldercare system (Kong \& Woods, 2018); to pessimistic views regarding economic marginalisation (Chong \& Ng, 2017) and challenges for the state in adapting to the mobility limitations in the elderly (Kang et al., 2016). Taken together, these studies aimed to improve or highlight gaps in Singapore's urban planning for 
eTropic 19.2 (2020) Special Issue: Sustainable Tropical Urbanism

betterment in aging and show a consensus in the importance of enhancing active and healthy aging strategies. The approaches to the issue share a focus in addressing the current 65 and over population. As a whole, the city-state's urban planning leans towards a 'help-them-now' strategy that is evident in government initiatives.

There is an absence of discourse on where Singapore stands in relation to the global initiatives for aging populations and whether the infrastructures developed based on the 'help-them-now' strategy will remain relevant by 2050. The objective of this paper is to step outside the global initiatives and open a fresh conversation for Singapore's emerging over 65 by 2050 population.

\section{Methodology}

To step outside the discourse of the initiatives it is critical to understand the behaviours and inclinations of Singapore's expanding aging populations, and to identify their evolving specific needs and desires. This belief undergirds urban planning and design strategies that are people-specific, contextually relevant, and applicable for 2050 . Such an analysis provides a pivotal background of the social morphology and evolving nature of the Singaporean environment for living, working, and playing. It comprises two parts:

Firstly, identifying current social morphology in Singapore by establishing the sociobehavioural trends and lifestyle diversification of the emerging over 65 by 2050 population through reviews of population statistics, housing demands, consumer reports and employment data. In this regard the paper considers secondary data related to:

- The current expanding 65 and over population's (first wave baby-boomers from the 1970s) evolving social behaviours and needs. These observations also contribute to understanding the origin of Singapore's lifestyle diversifications and the shifting inclinations in the current living, working, and playing environment.

- The current 35-44 years old population (which is the emerging over 65 by 2050 population, born in the 1990s and early 2000s) and their current social behaviours. These observations contribute towards indications on this age groups' probable future living, working, and playing inclinations, which enables an attempt to project a set of urban planning baseline criteria for this environment. 
eTropic 19.2 (2020) Special Issue: Sustainable Tropical Urbanism

Secondly, a comparative analysis of the urban planning baseline criteria between Singapore's 65 by 2050 population and UN and WHO global context for betterment in living for aging populations. This process includes:

- Establishing a set of urban planning criteria for Singapore based on observations and deductions from above.

- Reviewing the WHO Healthy Aging Strategy and Goals and the UN Sustainable Development Goals, and subsequently identifying their correlations in order to draw a set of urban planning baseline criteria developed in response to the guidelines and recommended practices.

- A comparative analysis of the two sets of baseline criteria for healthy aging and how they related to the verification of the stated hypothesis that these global initiatives are insufficient in addressing the specificity of Singapore's aging population.

\section{Social Morphology}

\section{The Expanding Aging Population of Singapore}

Singapore is a small tropical city-state close to the equator. However, unlike other tropical countries that are experiencing population growth rates around one third faster than the global average (Harding et al., 2016), Singapore is facing the population conundrum of temperate developed countries - a fertility rate decrease, coupled with a population that is living longer. By 2030, one in four residents (UOB Global Economics \& Markets Research, 2018) and about 40\% of the workforce will be 65 and over (Strategy Group, 2018). Veering from the typical inverted-V or mushroom-shape aging population diagram, there will be another transition in 2050 in Singapore. It is a second wave of aging population comprising Gen X and Millennials as illustrated in Error! Reference source not found.. Assuming a stereotypical inversed correlation of age to health and economic identity, according to the common scenario prescribed by UN and WHO, Singapore is currently experiencing incremental socio-economic pressure from a segment of non-contributing population; a general shrinking workforce that overloads the medical healthcare system. Singapore will face the same situation again in 2050.

However, this scenario may not be as dire for Singapore as UN and WHO indicators would predict. The country has continually made efforts to counter the pressures by providing a quality healthy aging environment through investment in elderly health and social care, development of age-inclusive flats within the public housing plan, and agefriendly urbanisation (Strategy Group, 2013). As Singapore's economy is people based (Yusuf \& Nabeshima, 2012), the Prime Minister's Office recognised potential 
socio-economic impacts of the population transition as early as 1992, and in 2015 set up a task force, the Strategy Group, to strengthen strategic alignments and priorities across public services. In 2016, the Strategy Group expanded to include the National Population and Talent Division (NPTD) that was tasked with achieving a sustainable and cohesive population that supports a vibrant economy with a strong Singaporean core inclusive of the aging population (Strategy Group, 2013).

Figure 1 Singapore Population Demographic Transition Charts for 1980, 2015 and 2050

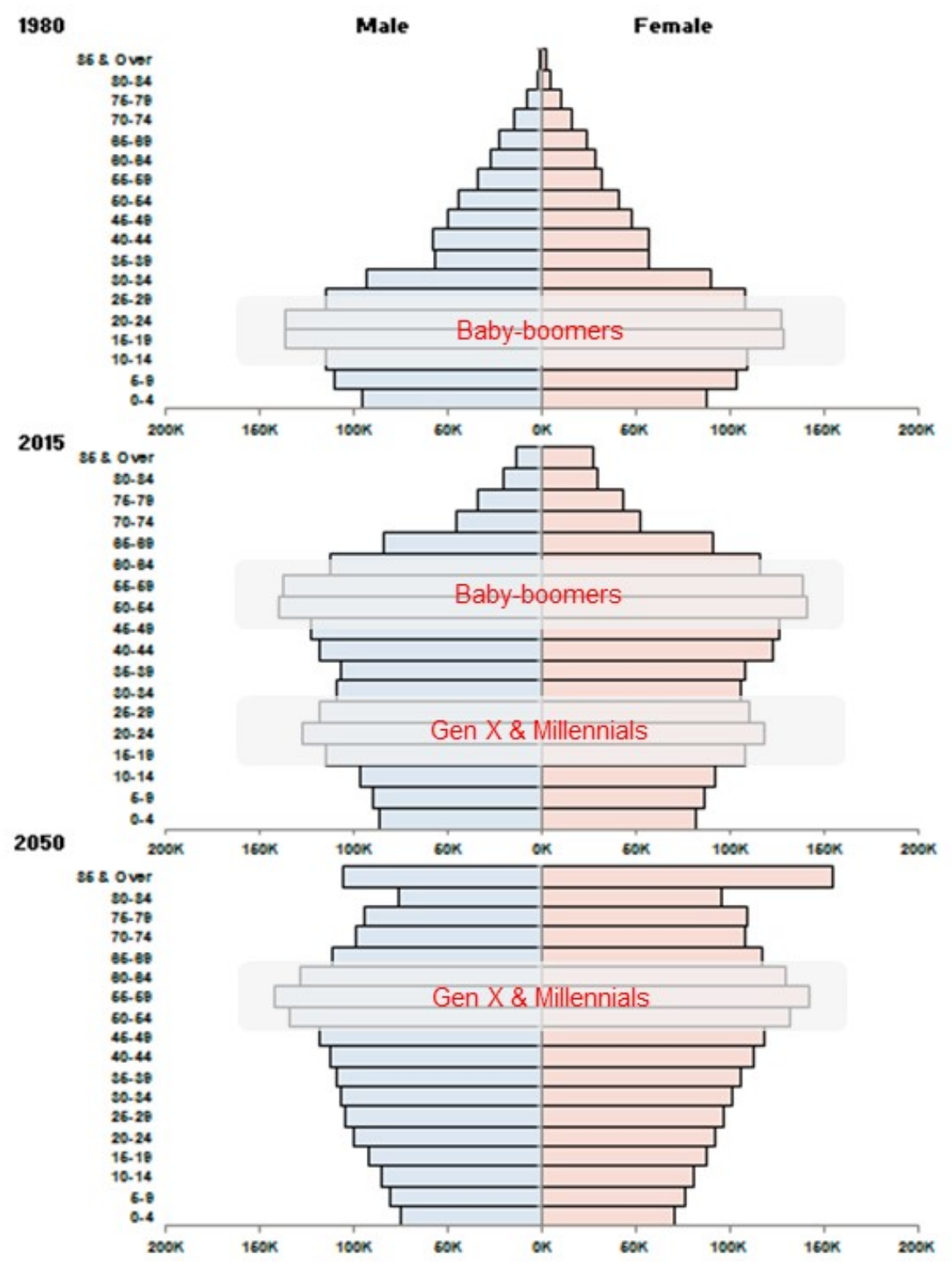

Singapore aging population transition with atypical inverted- $V$ or mushroom-shape population diagram indicating two waves of aging population in 2015 and 2050. Adapted from "M850581 Singapore Residents Aged 25 Years \& Over By Highest Qualification Attained, Sex And Age Group" (Singapore Department of Statistics, 2018a). 
eTropic 19.2 (2020) Special Issue: Sustainable Tropical Urbanism

In a comparative analysis of economic growth of small countries, Singapore's validated success is attributed to its portfolio of diversification and investment in human capital, knowledge and technologies (Yusuf \& Nabeshima, 2012). Singapore's current second place in Global Competitiveness rankings ${ }^{1}$ is attributed to high government and business efficiency with strong delivery of quality education, vocational training and sustainable skills development. It is ranked $9^{\text {th }}$ globally on the Human Development Index (public expenditure in percentage of GDP) and on education (United Nations Human Development, 2018). Social morphology influencers evolved through such efforts in sustaining the country's global competitiveness.

\section{Education and Professional Skill Levels}

Seeking continuous innovation Singapore invested in research capacity and promoting accessibility to tertiary education. It has attained $97.2 \%$ literacy rate among residents age 15 and above (Singapore Department of Statistics, 2018b), and just over $20 \%$ possess at least a degree, a diploma ${ }^{2}$ or a professional qualification. This is nearly a $100 \%$ increase from a decade ago.

\section{Life Expectancy and Health Level}

Currently, Singaporean life expectancy at age 65 is plus-21years, or 86 . The country is also seeing a decrease in general mortality rate at age 65 from cancer and cardiovascular diseases, and morbidity from age-related impairments, illnesses or diseases (Singapore Department of Statistics, 2018b).

\section{Digital \& Technology Revolutions}

Technology dominates the economy and people's lives. The International Monetary Fund (IMF) noted that Asia's regional economic outlook for the next decade will be largely influenced by the digital revolution (International Monetary Fund, 2018). Robotic automation, e-commerce and digitisation of finance will dominate the digital revolution landscape in Asia (Scherer, 2015). Singapore has also seen a surge in artificial intelligence and applications related to mobility, security, manufacturing, health, and sustainable, resilient systems. The increase is a result of the government's focus on becoming a smart nation (Varakantham et al., 2017).

\footnotetext{
1 World Economic Forum, WEF, 2019 Global Competitiveness Index of 140 countries. Variables include government, labor, trade, and other factors.

${ }^{2}$ Education and certifications, in an area of specialty, after Cambridge General Certificate of Education Advanced Level, US General Education Diploma, or equivalents.
} 
eTropic 19.2 (2020) Special Issue: Sustainable Tropical Urbanism

\section{Lifestyle Diversifications}

Through the social morphology identified above, Singaporeans are experiencing diversification in their ways of living, working, and playing as listed in the following subsections.

\section{Marriage, Parenthood and Social Relationships}

There is an inverse correlation between education, and marriage and parenthood, among Singaporeans - particularly for females. Younger educated Singaporeans who value freedom and independence remain unmarried and are inclined to view marriage as a personal choice. The study attributes the findings to education, workforce participation and income levels (Jones et al., 2012). This is evident among females who are marrying later in life ${ }^{3}$ (Jones et al., 2012; Strijbosch, 2015).

The high materialism index ${ }^{4}$ appears to dampen attitudes towards marriage and parenthood as individuals seek higher financial independence compare to higher opportunity costs associated with marriage and parenthood (Li et al., 2011). High costs of parenthood ${ }^{5}$ are discouraging factors in having an additional child, resulting in a falling birth rate since the late 1980s from 0.93 child per female of reproductive age to the current birth rate below 0.6 (Singapore Department of Statistics, 2018a).

A statistical study in Taiwan indicated an inverse correlation in time-factored economic-homeownership and fertility at marriage (Lo, 2011). This correlation shows the ease, or the lack of, in favouring parenthood as married couples gain financial stability and homeownership later in life. The rift period between getting married and achieving financial stability is expanding and impacts parenthood decisions negatively, particularly for females. The longer the rift, the lesser the chance of having children. In Singapore, this rift is exacerbated through the Housing \& Development Board $(\mathrm{HDB})^{6}$ applicant eligibility favouring nuclear families and legally married applicants (Housing \& Development Board, 2018a). Singles are tasked in first finding a partner and getting married prior to being eligible for new homes. The longer marriage is postponed, the longer the delays in homeownership and financial stability, and subsequently in parenthood; resulting in the compression of the window for

\footnotetext{
${ }^{3}$ The median age of first-time brides increased from 25.7 years old in 1998 to 28.1 in 2017 (Singapore Department of Statistics, 2018b).

${ }^{4}$ Research employs Richins \& Dawson's Materialism Scale (1992) common in marketing research and multiple scaled surveys.

${ }^{5}$ Costs in giving birth averages $\$ 8,000.00$, and raising a child 0 to 22 years old university graduate is estimated at $\$ 670,000.00$ in Singapore (Smart Parents, 2018).

${ }^{6}$ For a comprehensive history of the HDB, see (Kuah, 2018).
} 
eTropic 19.2 (2020) Special Issue: Sustainable Tropical Urbanism

motherhood. Extending the rift further, typical housing application averages 2.5 years. Fertility and personal preference are economic-time competitors in which the latter appears to be winning.

Singapore's above 50 year old singles population has increased 3.5 times during the last two decades (Error! Reference source not found.) from 40,000 in 2000 , to 144,000 (Singapore Department of Statistics, 2018b). The correlation analysis shows an increased demand for new HDB 1 and 2-Bedroom low-occupancy housing (Error! Reference source not found.). Though the increments can be attributed to overall population increase, the proportional increase in demand for low-occupancy housing by this age group indicates an emerging inclination among older populations towards independent living in smaller dwellings, separate from traditional nuclear family dwellings. This increasing population of mature aged singles, by-choice or through widowhood, is correlated to longer life expectancy. Later-in-life remarriage is still uncommon due to inherent negative socio-cultural and religious perceptions regarding remarrying (Mehta, 2002). Also, a common theme found among older Singaporeans who make the autonomous decision to live alone, with spouse or with an unrelated older person, is the preference or desire for the convenience and familiarity with their homes and neighbourhood, or aging-in-place and place attachment. Older Singaporeans increasingly do not want to burden their families and prefer to avoid potential conflicts (Tan et al., 2015). Whether it is socio-culturally influenced or through autonomy, there is a clear indication of a growing population in favour of personal privacy and individualism. Normalisation of this behaviour is gaining acceptance.

\section{Labour Force Participation, Delayed Retirement and Re-Skilling}

Between 2008 and 2018, the proportion of people 65 and over in the labour force increased by $72 \%$ (Singapore Department of Statistics, 2018b), or one in four working persons. More Singaporeans are also delaying retirement. Since the IMF 2018 Report (International Monetary Fund, 2018), which recommended revamping education to meet the demand for more flexible skill sets and lifelong learning, Singapore has raised the annual Continual Education and Training ${ }^{7}$ (CET) budget from SGD 600 million to SGD 1 billion for its 5.8 million population. This is to support transitions in growth and innovation while ensuring outcomes will improve welfare. Singaporeans have been engaged in lifelong learning since 1992 and the state continually demands and supports their efforts.

\footnotetext{
${ }^{7}$ Established in 1992, Continuing Education Training (CET), provides pre-employment training and continuing education to working adults to support economy diversification. In 2015, SkillsFuture was established as a national movement to provide opportunities in lifelong learning. Each resident would receive an annual S\$500 scholarship.
} 
eTropic 19.2 (2020) Special Issue: Sustainable Tropical Urbanism

Figure 2 Singapore Singles Population Aged 50 and above

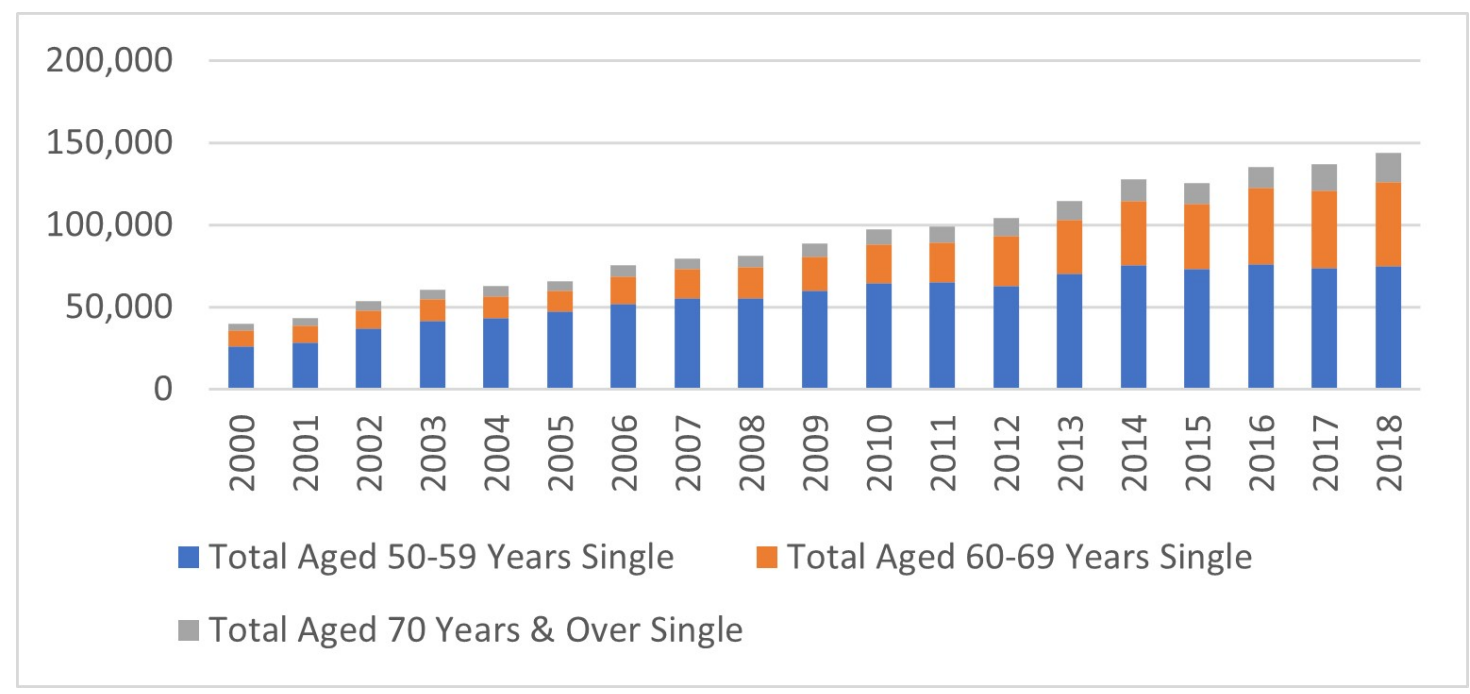

Increasing Singapore Singles Population by age group 50 years old and above, between 2000 and 2018; single by choice, widowhood or both (Singapore Department of Statistics, 2018b).

Figure 3 Demand for HDB 1 or 2-Bedroom Housing in Singapore

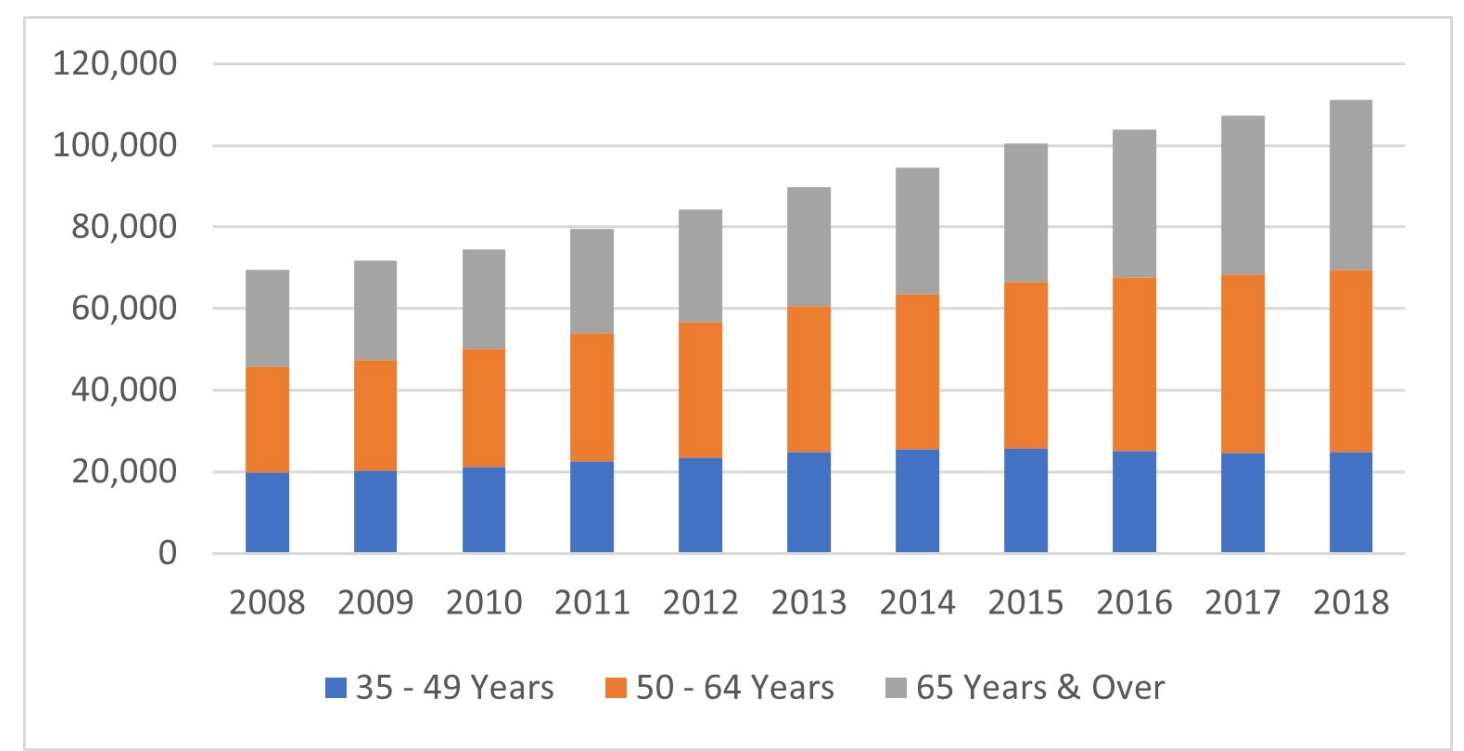

Increasing demand in Singapore Housing Development Board 1 or 2-bedroom low-occupancy housing by population of age 35 years and above ${ }^{8}$ (Singapore Department of Statistics, 2018b).

\footnotetext{
${ }^{8}$ HDB 1 or 2-bedroom dwellings were not available until 2000. Relative consistency in demand of such dwellings among the $35-49$ years old population is due to eligibility policy imposed by the HDB. Eligibility is restricted to citizens 55 years and over. An income capping policy also applies to protect lower income older citizens or retirees (Housing \& Development Board, 2018a).
} 
eTropic 19.2 (2020) Special Issue: Sustainable Tropical Urbanism

\section{Physical and Mental Wellness}

An initial study of older Singaporeans between 1995 and 2005 indicated that an increase in life expectancy is accompanied by an increase in mobility limitations (Yong et al., 2010). In a 2011 follow-up study (Kang et al., 2016) the team noted an increase in being ambulant and mobile for the same age group. The population was shown to have experienced morbidity compression in the latter study. The team attributed the improvement, compared to the population sample in the previous study, to the higher education levels and greater health resource awareness among baby-boomers. The influence on the compression will likely be even greater in the future. A QualityAdjusted Life Expectancy ${ }^{9}$ (QALE) study (Jo et al., 2019) in Korea also supported this direct correlation of education level with life expectancy and health level, particularly evident in metropolitan cities of Seoul and Daejeon.

According to Visa Singapore's press release on Visa Travel Insights Mapping the Future of Global Travel and Tourism in Asia Pacific, Singapore's 65 and over population are currently taking an average of 1.31 outbound leisure vacations annually. By 2025, this number is expected to increase to 2.84 , or over three million trips (Visa, 2016). This indicates the desire for leisure and physical activities among individuals in the aging population. Besides leisure, post-election random surveys indicate that the percentage of voters aged 65 and over has doubled from $8 \%$ to $17 \%$ over the past three elections (Lee Kuan Yew School of Public Policy, 2006, 2011 \& 2015). Both Visa's report and the post-election surveys affirm the increasing social and cultural awareness and political participation of these individuals. Therefore, as education levels in the aging population rise, it is possible to assert that aging Singaporeans can no longer be presumed to be deteriorating in overall physical and mental health.

\section{Digital Lifestyle}

According to an analysis of artificial intelligence (Al) of smart home applications in China's information technology (IT) economy-hub city of Chengdu, the future of Al is about improving efficiency, diversification and humanness for deeper embedding into human lives (Song \& Li, 2018). Song and Li's analysis is critical to Singaporeans as they are one of the most digitally active populations in the world. The 2007-2017 internet penetration (percentage of population as internet users) increased from $68 \%$ to $84 \%$ (Singapore Info-Communications Media Development Authority, 2018). This

\footnotetext{
${ }^{9}$ Quality-Adjusted Life Expectancy (QALE) means life expectancy reflecting health-related quality of life and is one of the indicators of healthy life expectancy and population health level. The Korean study determined QALE trends by age, gender, education level and sub-region from 2005 to 2013.
} 
eTropic 19.2 (2020) Special Issue: Sustainable Tropical Urbanism

internet digital acclimation is prevalent among Gen X and Millennials (35 - 44 years old) as seen in Error! Reference source not found. (IMDA, 2019) and Error! Reference source not found. (statista, 2016). Al smart home integration among Singaporeans is on the rise and likely to be implemented with ease. To hasten this development, the HDB has inked three new research projects with industry partners at the World Cities Summit in an effort to advance smart and sustainable homes for Singaporeans (Housing \& Development Board, 2018b). Smart eldercare is also valued by the state as the facilitator for aging-in-place, but requires a contextual approach to its design, development and implementation (Kong \& Woods, 2018).

Table 1 Singapore Infocomm Usage by Households and Individuals Survey

\begin{tabular}{lllll}
\hline Age Group & $\begin{array}{l}\text { Internet } \\
\text { Users }\end{array}$ & $\begin{array}{l}\text { Smartphone } \\
\text { Users }\end{array}$ & $\begin{array}{l}\text { Using Portable } \\
\text { Equipment to Connect to } \\
\text { the Internet Wirelessly }\end{array}$ & $\begin{array}{l}\text { Online } \\
\text { Shoppers }\end{array}$ \\
\hline $35-49$ & $98 \%$ & $100 \%$ & $99 \%$ & $84 \%$ \\
$50-59$ & $88 \%$ & $98 \%$ & $96 \%$ & $54 \%$ \\
$60+$ & $55 \%$ & $76 \%$ & $69 \%$ & $29 \%$ \\
\hline \multicolumn{5}{c}{$($ IMDA, 2019) }
\end{tabular}

Table 2 Daily Internet Usage Rate in Singapore in 2016, by age group

\begin{tabular}{lc}
\hline Age Group & Access Internet Daily \\
\hline $35-44$ & $92 \%$ \\
$45-54$ & $86 \%$ \\
$55+$ & $78 \%$ \\
\hline
\end{tabular}

\section{Urban Planning Baseline Criteria Comparative Analysis}

\section{Singapore Extended Lifespan Population Baseline Criteria}

From the preceding sections, one can conclude that Singapore's expanding aging population is inclined to be physically and mentally healthy, educated, skilled, reskilling and working. These Singaporeans are also likely to be active, desire stimuli, and value freedom and independence. Their independent, active, and healthy or mobile phase, which is usually associated with youthfulness in a typical lifespan, is extended. The current aging baby-boomer Singaporean is quite unlike the stereotypical grandparents of the past. The phase of morbidity associated with old age is postponed. Hence, it would be more appropriate to identify Singapore's 65 and over aging population, current and future, as the Singapore Extended Lifespan Population 
eTropic 19.2 (2020) Special Issue: Sustainable Tropical Urbanism

(SELP). This population's lifespan has an extended 65 and over period that is healthy and active for longer, before morbidity and passing (Error! Reference source not found.). Therefore, based on these observations, the SELP possesses and values the following characteristics and qualities: independence, employability, continual learning and opportunities, social activeness and cultural awareness, mobility, capacity in digital acclimation and $\mathrm{Al}$ integration, and financial capacity.

Figure 4 SELP Lifespan relative to Typical Aging Lifespan

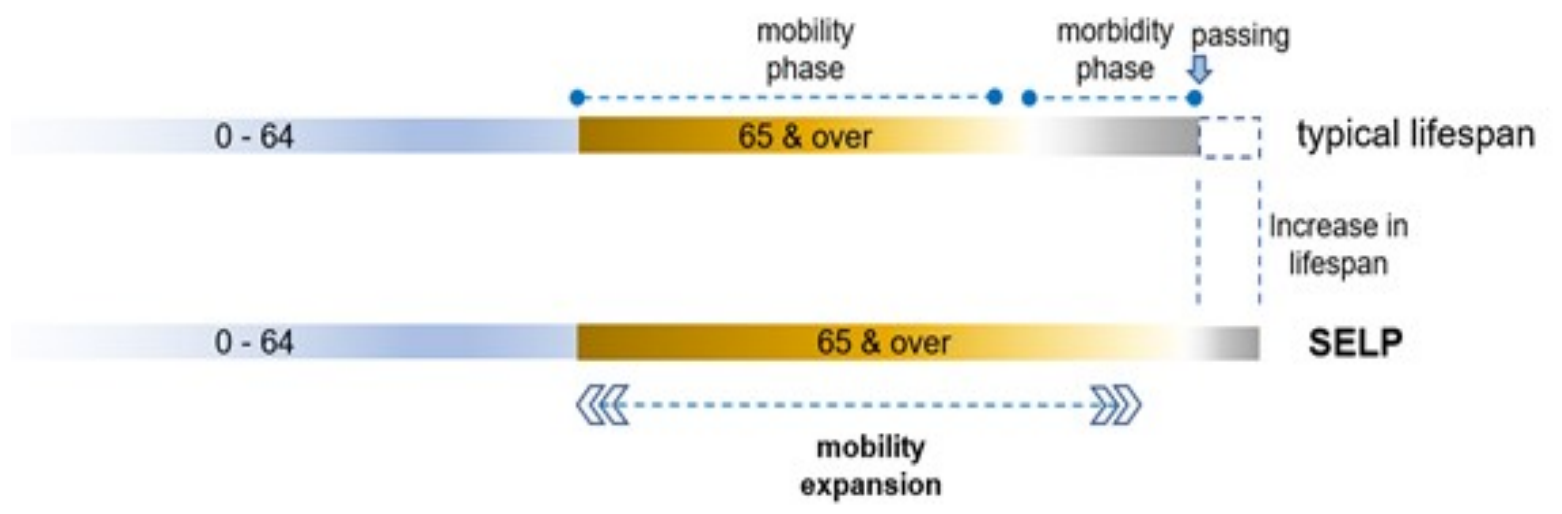

Arbitrary timeline illustration depicting mobility expansion and increased longevity in SELP lifespan relative to a typical aging lifespan.

Extrapolating from these values for the SELP of 2050, one can anticipate further normalisations in singlehood and independent living. With the state's vigorous championship in re-skilling, it is highly probable that more than $20 \%$ of Singapore's extended lifespan population will possess a university degree, diploma or be professionally skilled and participating in lifelong learning and reskilling. Al will be embedded in their lives. Therefore, the urban planning baseline criteria for SELP will be required to provide environments supportive of these values in:

- Autonomy with preference for independence in living arrangements.

- Productivity in work through maintaining good physical and mental health with social and cultural awareness.

- Learning and education with skill acquisition to maintain relevance with the general workforce or personal aspiration.

- Technology integration with openness in engaging smart technology and new digital applications.

- Materialism with expanded consumer power from extended income generation capacity.

- Individualism with preference for privacy. 
eTropic 19.2 (2020) Special Issue: Sustainable Tropical Urbanism

\section{UN and WHO Global Initiatives Derived Baseline Criteria}

In order to understand the Singapore situation within the global aging discourse this section identifies the $\mathrm{WHO}$ and UN global initiatives, and correlates their intents, strategies and goals within the recommended practices on 'Healthy Aging'. Subsequently the paper is able to formulate a set of criteria for urban planning based on these initiatives for global healthy aging.

The Global Strategy and Action Plan on Aging and Health was endorsed by the World Health Assembly in 2016 and is relevant to the specific aspects of the UN Sustainable Development Goals which are "an integrated, indivisible set of global priorities for sustainable development" (WHO, 2017, p.1 item 2) and include a focus on functional ability, extending mortality and improving health of older people. The initial 'Active Aging' (WHO, 2002) framework was replaced by 'Healthy Aging' in 2015 to create environments and opportunities that enable people to be and do what they value throughout their lives. This updated framework defined healthy aging as "...the process of developing and maintaining the functional ability that enables well-being in older age" (World Health Organization, 2017, p.28). This functional ability is determined by the intrinsic capacity of the individual, the inhabiting environments, and interactions to:

- Meet their basic needs.

- Learn, grow, and make decisions.

- Be mobile.

- Build and maintain relationships.

- Contribute to society.

The individual's intrinsic capacity comprises both psychological and physiological capacities. It is influenced by health, socio-economic, cultural, or environmental conditions, and any related predispositions. Successful Aging focuses on the biological benefits of keeping healthy and staying engaged in all kinds of activities. Productive Aging emphasises social integration and policy responses in aging labour market and family structures (Ko \& Yeung, 2019). The WHO (2017) also promoted the platform of information on environments to meet the strategies with age-friendly environments and practices. Age-friendly environments are free from physical and social barriers and supported by policies, systems, services, products and technologies that promote health, physical, and mental capacity across the life-course, and enable people to continue to do the things they value while promoting older people's inclusion and contribution to all areas of community life (WHO, 2017). 
eTropic 19.2 (2020) Special Issue: Sustainable Tropical Urbanism

The WHO Global Strategy and Action Plan for Healthy Aging contributed to several UN Sustainable Development Goals (United Nation, 2015) in correlated declarations to empower vulnerable people, including old people, to improve their physical and mental health and wellbeing, and to extend life-expectancy for all (see appendix $A$ for a list of correlations). It provides a framework for coordinated global action towards a world in which everyone can live a long and healthy life, and to maximize functional ability. The strategy focuses on five strategic objectives, and implementation is underpinned by the principles of human rights, equity, and non-discrimination (particularly based on age), gender equality, and intergenerational solidarity. Furthermore, a set of 10 priorities of concrete action and an agenda creating platform in helping different countries was introduced (WHO Department of Ageing and Life Course, 2017).

With emphasis on human rights, equity and respect for older people, the UN and WHO baseline criteria for urban planning and design in regards to Healthy Aging goals can be distilled as:

- Extending mortality, maximize functional ability and ensure healthy lives and wellbeing in old age.

- Providing equitable, integrated, and inclusive environments that foster healthy and active aging and life-long learning void of poverty and hunger.

- Creating age-friendly environments that support the Health Aging goals, free of physical and social barriers (WHO, 2017).

The UN and WHO concerns are fundamental and elementary for survival. Their objectives could be conclusively summarised as the baseline criteria and context for the purposes of this study as:

- Mortality and health.

- Functional ability.

- Security, human rights and inclusiveness.

- Basic needs and opportunities.

- Age-friendly environments.

\section{Findings}

A comparison of the baseline criteria in Table 2, reveals that the Singapore Extended Lifespan Population (SELP) is striving for different aspects of living, working, and playing from those emphasised by the UN and WHO. The SELP's departure is prominent, and in principle justifies this paper's hypothesis that the global initiatives do not adequately address the Singapore scenario. 
eTropic 19.2 (2020) Special Issue: Sustainable Tropical Urbanism

Table 3 Comparisons of Aspects of Living and Baseline Criteria in Urban Planning

\begin{tabular}{|c|c|}
\hline SELP aspects of living & UN and WHO aspects of living \\
\hline Independence & $\begin{array}{l}\text { Extend mortality, maximize functional } \\
\text { ability, and ensure healthy lives and }\end{array}$ \\
\hline Employability & wellbeing in old age. \\
\hline Continual learning \& opportunities & $\begin{array}{l}\text { Equitable, integrated, and inclusive } \\
\text { environments that foster healthy \& active }\end{array}$ \\
\hline $\begin{array}{l}\text { Social activeness \& cultural awareness } \\
\text { mobility }\end{array}$ & $\begin{array}{l}\text { aging and life-long learning void of poverty } \\
\text { and hunger. }\end{array}$ \\
\hline Digital acclimation \& Al integration & $\begin{array}{l}\text { Age-friendly environments that support the } \\
\text { Health Aging goals, free of physical and }\end{array}$ \\
\hline Financial capacity & social barriers. \\
\hline SELP Urban Planning & UN and WHO Urban Planning \\
\hline Baseline Criteria & Baseline Criteria \\
\hline Individualism & Mortality \& health \\
\hline Work, social \& cultural productivity & Functional ability \\
\hline Learning and education & Security, human rights \& inclusiveness \\
\hline Technology integration & Basic needs \& opportunities \\
\hline Materialism & Age-friendly environment \\
\hline
\end{tabular}

Lifelong learning is the common criteria in both sets of data. However, for Singapore, lifelong learning is an economic diversification strategy to ascertain global competitiveness while ensuring stable social welfare. It also started two decades prior to the UN declaration, and was aimed at improving one's employability so as not to fall into poverty. To categorise the Singapore and UN 'lifelong learning' as similar would be highly inequitable as their contexts vastly differ. In the 2019 Quality of Living Ranking, Singapore is ranked $25^{\text {th }}$ globally and it is the only tropical city in Asia ranked in the top 50 cities (Mercer, 2019). A survey among 1,038 Singaporeans in 2006 (Tambyah et al., 2009) noted concerns about the overall quality of life in relationships, homeownership and enhancement of lifestyles. The survey also showed the common notion of 'being healthy' among the participants is limited to having healthy diets and 
eTropic 19.2 (2020) Special Issue: Sustainable Tropical Urbanism

participating in routine physical exercise. This indicates adequate availability in food and basic medical care in the population.

Singapore is in a league of its own with criteria that demand an alternate contemplation in urban planning and design for 2050. Although there are criticisms of the Singapore government's anti-welfare policies and socio-politically controlled retirement and healthcare governance (Chong \& $\mathrm{Ng}, 2017$ ), which have been debated as infringements of human rights, these socio-political discussions are not included in the scope of this paper. The focus is on the urban planning context.

\section{Discussion}

\section{Impacts \& Challenges}

As this paper relies on deductive association and interpretation of secondary data, reports, and research literature, the analysis and findings remain theoretical. Nevertheless, the statistical findings of the Baby-Boomers Survey (Chan \& Yap, 2009) prepared for Singapore's Ministry of Community, Youth and Sports (MCYS) (restructured in 2012 to become the Ministry of Social and Family Development (MSF)), resonate with the interpretations and the criteria established in this analysis. It should be noted that Chan and Yap (2009) surveyed baby-boomers with the same living contexts and engaged similar proxies that are used in this paper to determine the baby-boomers' socio-behavioural inclinations.

Although their report was purely informative and provided no recommendations, the Singapore Government took note of Chan and Yap's findings and began launching strategies to meet the baby-boomers' emerging needs. In 2015, HDB launched lowoccupancy housing catering to the elderly and enhanced the Lease Buyback Scheme ${ }^{10}$ along with advancing smart-home technology integration in 2018. In 2016, the city-state's Workforce Development Agency was reconstituted in collaboration with the Ministry of Manpower (MOM) and Ministry of Education (MOE) with the aim to achieve a healthy Continuing Education \& Training (CET) ecosystem in Singapore (Ministry of Manpower, 2016) with greater emphasis on age-inclusion. The BabyBoomers Survey was impactful and influenced cross-disciplinary adaptations.

Urban planning and design impact many aspects of life across living, playing, and working. Whether the intention is to initiate a process, facilitate progress, nudge an evolution, or alter socio-environmental behaviour, urban planning and design and their

\footnotetext{
10 The scheme allows $55-\&$-above elderly homeowners who wish to continue to live in their HDB homes while making available the value of their properties by receiving cash and higher pay-outs from the government mandated personal savings Central Provident Fund (CPF) for a lease period till the age of 95.
} 
eTropic 19.2 (2020) Special Issue: Sustainable Tropical Urbanism

background working contexts, are pivotal to success. Didactic standard-upgrades and choice-expansions in Singapore public housing and social environments are insufficient in addressing the needs of an aging population (Harrison, 1997). It would be even more so for the Singapore Extended Lifespan Population (SELP) with their diversified lifestyles and augmented living standards and expectations. Hence, understanding their behaviours and inclinations is critical in providing supportive environments that would be successfully relevant and sense-making to this population.

An empathic approach is a potential key to unravelling the socio-psycho-physioeconomic fabric in revealing relevance and sense-making to the SELP in life, work, and play. Empathic design originates from the New Product Development (NDP) industry. In principle, it is a user-centred design approach that is directed towards building creative understanding of users and their everyday lives for new product development (Postma et al., 2012). Empathic design emphasises the importance of emotional connections between the designers and the inhabitants, and the need to understand the social and cultural aspects for design creation (Sandman et al., 2018). However, Postma, Zwartkruis-Pelgrim, Daemen and Du (2012) identified challenges in stakeholders transitioning from rational hard-facts to a holistic qualitative-inputs approach involving extensive and costly user-experience research.

Empathy is also critical in medical and long-term care planning. In their quantitative study of internet-mediated lifestyle interventions, Aalbers, Baars and Rikkert (2011) concluded that such programs hold great potential in reaching large populations of older people. Remote health monitoring through sensors (Dang et al., 2009), virtual interaction (Spinsante \& Gambi, 2012) or smart home gateway technology (Guan et al., 2017) for the elderly are of great interest to many national healthcare and longterm care systems seeking to minimise human labour and costs as they face disproportionately high elderly populations. Conceived in 2014, the Singapore Housing Development Board (HDB) will roll out new housing with digital infrastructure ready for the Elderly Monitoring System (EMS) by 2020 as part of the agency's progress towards smart living. The system allows connective monitoring of elderly people with caregivers. Empathic design will alter the genesis of roadmaps in urban planning and design, influencing public governance and financial investment interests.

The idea of empathy and design, or empathic design, a user-centred approach in product and service development, has drawn great interest among designers and engineers (Brown, et al., 2019). It involves analysing users' interactive behaviours and emotions with a product. Understanding the baseline criteria is in essence a primitive attempt in empathic design. Drawing on Tuan's (1977) classical work, Brown et al. (2019) proposed that human-environment relationships, or place attachment, can be enhanced through empathy towards self-identity and place-identity. Tuan's empathic 
eTropic 19.2 (2020) Special Issue: Sustainable Tropical Urbanism

analysis is not specific to Singapore and this approach, which has universal resonance, can be applied to other cities facing similar dynamic social morphology in developing meaningful urban planning and design principles in supporting and sustaining the uniqueness of each city.

\section{SELP: Burdens or Possibilities?}

If urban planning and design applications for Singapore's extended lifespan population can impact so many aspects of product development, is it limiting to view SELP urban planning and design simply as inevitable socio-economic evolution and a transformation driver. In this analysis SELP is not a burden but an igniter of creativity. Such ideology is not novel. Economists and researchers in the Netherlands (Klaassen \& Van der Vlist, 1990) and the United States (Kresl \& letri, 2009) have argued that an aging population is potentially a market economy driver. With state stability accompanied by supportive governance, SELP is a possible creator in the future of urban planning and design. SELP could be highly influential in determining the development of products ranging from lifestyles to the environment. Understanding this population's needs and forecasting their inclinations will provide powerful marketing and consumerism tools. However, as with empathic design, stakeholders are likely to view such research efforts as costly.

\section{Limitations and Further Studies}

\section{Limitations}

As previously highlighted, the interpretations in this paper have relied on secondary data, reports, and research references. The findings remain theoretical based on associative deductions. The only supporting evidence is in the Baby-Boomers Survey (Chan \& Yap, 2009) which validates this paper's engaged proxies, interpretations, deduced contexts and baseline criteria, but only for the current 65 and over population. This research assumes that the over 65 by 2050 population will follow a similar trajectory in evolving needs.

With the large volume of diverse information, this analysis has encountered multiple occasions in foregoing various urban and social aspects of planning in order to concentrate on the main theme in identifying the SELP and their characteristics which are distinguishable from the UN and WHO prescribed healthy aging strategy. Planners and designers may find the approach taken here as policy-focused and lacking discussion regarding the place-making and architectural core of urban planning and design. However, the fundamental purpose of this paper is verification of the 
eTropic 19.2 (2020) Special Issue: Sustainable Tropical Urbanism

applicability of UN and WHO strategy and goals to the SELP, rather than a design or an environmental sustainability evaluation.

Singapore is a racially and culturally diverse tropical city, this research has excluded the distinction of possible ethno-cultural and other influences on social behaviour. Such an inclusion would have expanded the research considerably, and in this instance lies beyond the scope of the paper. The elderly population that is in poverty and/or requiring long-term care has also not been discussed. These sub-groups of the SELP are worthy of independent conversations as the subject infringes upon public policies regarding indigenous minority populations (Lee, 2001) and active aging (Aw, et al., 2017). Likewise, societal impacting factors such as natural calamities, pandemics and major economic shifts would be more aptly addressed within social and disaster resilience issues.

\section{Future Field Validation, Integration and Sustainability}

The baseline criteria drawn from this study would be best tested in future qualitative studies on the current 34 year old population, who will be the 65 by 2050 SELP. This could be undertaken through field collection of fundamental criteria of their current beliefs and urban practices of living, working and playing, in order to provide a quantitative study similar to, or based on, the Baby-Boomers Survey (Chan \& Yap, 2009). Comparisons between this paper's findings and the 65 by 2050 data will determine any addressable criteria gaps, or even retrospectively falsify the research's current hypothesis. If the 65 by 2050 study supports the initial hypothesis, the baseline criteria can be further compared against the Master Plan 2019 (Urban Redevelopment Authority, 2019). This can provide further insights to possible integrations of the SELP criteria and supplement aspects of environmental sustainability, policymaking, and planning and design principles.

\section{Conclusions}

Identifying the baseline criteria is essential. An alteration in the criteria can shift the paradigm of urban planning and design that would impact public and private living domains for individuals, groups, and communities. It is also important to recognise the baseline criteria as temporal because they change with each emerging population of different people with different needs. Instead of trying to catch-up or patch-up any gaps with the changing population and its demands, it would be beneficial to consider future baseline criteria derived from empathic design as a means of reducing potential costs from irrelevant development and construction. Bureaucracy, development, and construction need to project ahead in order to meet a target population's needs on time before the group passes on. 
eTropic 19.2 (2020) Special Issue: Sustainable Tropical Urbanism

The Baby-Boomers Survey (Chan \& Yap, 2009) demonstrated such an opportunity in urbanisation which the Singapore Government responded to by adjusting urban plans over the past decade. Chan and Yap (2009) provided an array of revealing descriptions regarding the emerging population-specific needs and behaviours of the baby-boomer population, which prompted intersectoral governance adaptations before the population reached 65 . A similar survey needs to be repeated with the current population who will comprise the 65 by 2050 population. The survey findings may ignite creative, anticipatory, and interdisciplinary development planning in urbanism. The theoretical interpretative methodology of this paper, substantiated with statistical survey methods, deserves to be given further consideration. Such an approach sets roadmaps towards establishing probable environments and provide space for developing preventative measures in urban planning policies, or positive environmental-behaviour encouragement strategies. Furthermore, new urban lifestyle identifications can benefit the development and engineering of other relevant products and services, which, in turn, would provide opportunities for the expansion of silver consumerism. The Singapore Extended Lifespan Population, as with many other aging populations, are likely to advance their status in economic significance and social importance. 
eTropic 19.2 (2020) Special Issue: Sustainable Tropical Urbanism

\section{References}

Aw, S., Koh, G., Oh, Y. J., Wong, M. L., Vrijhoef, H. J., Harding, S. C., Geronimo, M.A.B., Lai, C.Y.F., \& Hildon, Z.J.L. (2017). Explaining the continuum of social participation among older adults in Singapore: from 'closed doors' to active ageing in multi-ethnic community settings. Journal of Aging Studies , 42, 46-55. https://doi.org/10.1016/j.jaging.2017.07.002

Brown, K., Adger, W. N., Devine-Wright, P., Anderies, J. M., Barr, S., Bousquet, F., Butler, C., Evans, L., Marshall, N., \& Quin, T. (2019). Empathy, place and identity interactions for sustainability. Global Environmental Change , 56, 11-17. https://doi.org/10.1016/j.gloenvcha.2019.03.003

Chan, A., \& Yap, M. T. (2009). Baby-Boomers Survey. National University of Singapore, Lee Kuan Yew School of Public Policy, Ministry of Community Development, Youth and Sports. Singapore: National Archives of Singapore.

Chong, Y. K., \& Ng, I. Y. (2017). Constructing poverty in anti-welfare Singapore. Social Identities , 23 (2), 146-162. https://doi.org/10.1080/13504630.2016.1207514

Dang, S., Dimmick, S., \& Kelkar, G. (2009). Evaluating the evidence base for the use of home telehealth remote monitoring in elderly with heart failure. Telemedicine journal and e-health : the official journal of the American Telemedicine Association , 15 (8), 783-796. https://doi.org/10.1089/tmi.2009.0028

Guan, K., Shao, M., \& Wu, S. (2017). A Remote Health Monitoring System for the Elderly Based on Smart Home Gateway. Journal of Healthcare Engineering , 2017, 1-9. https://doi.org/10.1155/2017/5843504

Harding, S., Bird, G., Losos, E., Aderolili, R., \& Hotez, P. (2016). International Day of the Tropics: Towards a Better Global Future. Tropic: electronic journal of studies in the tropics , 15 (2), 5-12. https://doi.org/10.25120/etropic.15.2.2016.3538

Harrison, J. D. (1997). Housing for the ageing population of Singapore. Ageing International , 23 (3), 32-48. https://doi.org/10.1007/s12126-997-1003-4

Housing \& Development Board. (2018a). Housing \& Development Board. Retrieved from Eligibility - Housing Development Board (HDB) https://www.hdb.gov.sg/cs/infoweb/residential/buying-a-flat/new/eligibility

Housing \& Development Board. (2018b). Singapore: HDB Inks Three Research Agreements to Advance Smart and Sustainable HDB Homes. Singapore: Housing \& Development Board.

IMDA. (2019). Annual Survey on Infocomm Usage In Households and By Individuals for 2019. Retrieved from Infocomm Media Development Authority: https://www.imda.gov.sg/infocomm-media-landscape/research-and-statistics/surveyreports

International Monetary Fund. (2018). Regional Economic Outlook. Asia and Pacific: Asia at the Forefront: Growth Challenges for the Next Decade \& Beyond. Washington, DC: IMF Publication.

Jo, M.-W., Seo, W., Lim, S. Y., \& Ock, M. (2019). The Trends in Health Life Expectancy in Korea according to Age, Gender, Education Level and Subregion: Using QualityAdjusted Life Expectancy Method. Journal of Korean Medical Science , 34 (Suppl 1). https://doi.org/10.3346/jkms.2019.34.e88

Jones, G. W., Yanxia, Z., \& Zhi, P.C.P. (2012). Understanding high levels of singlehood in Singapore. Journal of Comparative Family Studies , 43 (5), 731-750. https://doi.org/10.3138/jcfs.43.5.731

Kang, S-H., Yong, V., Chan, A., \& Saito, Y. (2016). Revisiting Mobility Limitations of Seniors in Singapore, 1995 to 2011. Gerontology and Geriatric Medicine, 2. https://doi.org/10.1177/2333721416645034 
eTropic 19.2 (2020) Special Issue: Sustainable Tropical Urbanism

Klaassen, L. H., \& Van der Vlist, J. A. (1990). Senior Citizens: A Burden? De Economist, 138 (3), 302-320. https://doi.org/10.1007/BF01857778

Ko, P.-C., \& Yeung, W.-J. J. (2019). Contextualizing Productive Ageing in Asia: Definitions, Determinants and Health Implications. Social Science \& Medicine , 229, 1-5. https://doi.org/10.1016/i.socscimed.2019.01.016

Kong, L., \& Woods, O. (2018). Smart eldercare in Singapore: Negotiating agency and apathy at the margins. Journal of Aging Studies , 47, 1-9. https://doi.org/10.1016/j.jaging.2018.08.001

Kresl, P. K., \& letri, D. (2009). Ageing of the Population: Good News for Cities. Local Economy: The Journal of the Local Economy Policy Unit , 24 (6-7), 652-636. https://doi.org/10.1080/02690940903354015

Kuah, A.T.H. (2018). Tropical Urbanisation and the Life of Public Housing in Singapore. eTropic: electronic journal of studies in the tropics , 17 (1), 41-59. https://doi.org/10.25120/etropic.17.1.2018.3641

Lee Kuan Yew School of Public Policy. (2006, 2011 \& 2015). IPS Post Election Surveys 2006, 2011, 2015. Singapore: Institute of Policy Studies.

Lee, W. K. (2001). The Poor in Singapore: Issues and Options. Journal of Contemporary Asia , 31 (1), 57-70. https://doi.org/10.1080/00472330180000041

Li, N. P., Patel, L., Balliet, D., Tov, W., \& Scollon, C. N. (2011). The Incompatibility of Materialism and the Desire for Children: Psychological Insights into the Fertility Discrepancy Among Modern Countries. Social Indicators Research , 101 (3), 391404. https://doi.org/10.1007/s11205-010-9665-9

Lo, K.-T. (2011). The Crowding-out Effect of Homeownership on Fertility. Journal of Family and Economic Issues , 2012 (33), 108-117. https://doi.org/10.1007/s10834-0119256-1

Mehta, K. K. (2002). Perceptions of Remarriage by Widowed People in Singapore. Ageing International , 27 (4), 93-107. https://doi.org/10.1007/s12126-002-1017-x

Mercer. (Mar, 2019). Quality of Living City Ranking. Retrieved 12 Jan, 2020, from Global Mobility Solutions, Mercer: https://mobilityexchange.mercer.com/Insights/quality-ofliving-rankings

Ministry of Manpower. (25 Oct, 2016). Refreshed Continuing Education and Training (CET) Masterplan. Retrieved $14 \mathrm{Dec}$, 2019, from Ministry of Manpower: https://www.mom.gov.sg/employment-practices/skills-training-anddevelopment/refreshed-cet-masterplan

Strategy Group (2013). A Sustainable Population for a Dynamic Singapore: Population White Paper. The Prime Minister's Office, Singapore National Population and Talent Division.

Postma, C. E., Zwartkruis-Pelgrim, E., Daemen, E., \& Du, J. (2012). Challenges of doing empathic design: Experiences from industry. International Journal of Design , 6 (1), 59-70.

Strategy Group. (2018). Population in Brief 2018. Prime Minister's Office, Singapore.

Sandman, H., Levanen, J., \& Savela, N. (2018). Using Empathic Design as a tool for urban sustainability in low-resource settings. Sustainability (Switzerland) , 10 (7), 24932517. https://doi.org/10.3390/su10072493

Scherer, M. U. (2015). Regulating artificial intelligence systems: risks, challenges, competencies, and strategies. Harvard Journal of Law \& Technology , 29 (2), 353. https://doi.org/10.2139/ssrn.2609777

Singapore Department of Statistics. (2018a). M850581 Singapore Residents Aged 25 Years \& Over By Highest Qualification Attained, Sex And Age Group. Singapore:

Department of Statistics. 
eTropic 19.2 (2020) Special Issue: Sustainable Tropical Urbanism

Singapore Department of Statistics. (2018b). SingStat Table Builder HomePage. Retrieved 15 02, 2019, from Department of Statistics Singapore:

https://www.tablebuilder.singstat.gov.sg/publicfacing/mainMenu.action

Singapore Info-Communications Media Development Authority. (04 July, 2018). InfoCommunications Development Authority. Retrieved from Infocomm UsageHouseholds and Individuals: https://www.imda.gov.sg/industry-development/factsand-figures/infocomm-usage-households-and-individuals\#3

Smart Parents. (June, 2018). How much does it cost to raise a child in Singapore? Retrieved 30 Oct, 2020, from Smart Parents: https://www.smartparents.sg/parenting/moneysmarts/how-much-does-it-cost-raise-child-singapore-infographic

Song, J., \& Li, Y. (2018). Artificial Intelligence and Modern Home Design. MATEC Web of Conferences. 227, p. 02004. Xi'an, China: EDP Sciences. https://doi.org/10.1051/matecconf/201822702004

Spinsante, S., \& Gambi, E. (2012). Remote health monitoring for elderly through interactive television. BioMedical Engineering Online , 11 (1), 54-72. https://doi.org/10.1186/1475-925X-11-54

statista. (26 Jun, 2016). Daily internet usage in Singapore by age group 2016. (Statista Research Department) Retrieved 02 Nov, 2020, from statista: https://www.statista.com/statistics/348101/daily-internet-usage-age-group-singapore/

Tambyah, S. K., Tan, S. J., \& Kau, A. K. (2009). The Quality of Life in Singapore. Social Indicators Research , 92 (2), 337-376. https://doi.org/10.1007/s11205-008-9347-z

Tan, K. K., He, H. G., Chan, S. C., \& Vehvilainen-Julkunen, K. (2015). The experience of older people living independently in Singapore. International Nursing Review , 62 (4), 525-535. https://doi.org/10.1111/inr.12200

Tuan, Y. (1977). Space and Place: Perspective of Experience. Minneapolis: University of Minnesota Press.

United Nation. (2015). Transforming our World: The 2030 Agenda for Sustainable Development. (pp. 14-28). Geneva: United Nations.

United Nations Human Development. (2018). Human Development Indices and Indicators: Statistical Update. New York City: Human Development Report Office.

UOB Global Economics \& Markets Research. (2018). Quaterly Global Outlook 1Q2018 Singapore Focus: Reaching A Demographic Crossroad in 2018. Singapore: United Overseas Bank.

Urban Redevelopment Authority. (27 Nov , 2019). Master Plan. Retrieved 30 Oct, 2020, from Urban Redevelopment Authority: https://www.ura.gov.sg/Corporate/Planning/MasterPlan

Varakantham, P., An, B., Lo, B., \& Zhang, J. (02 Oct, 2017). Artificial intelligence research in Singapore: Assisting the development of a smart nation. Al Magazine , 38 (3), 102105. https://doi.org/10.1609/aimag.v38i3.2749

Visa. (10 May, 2016). Singapore Households Estimated to be World's 7th Top Overseas Travel Spenders by 2025. Retrieved from Visa: https://www.visa.com.sg/aboutvisa/newsroom/press-releases/singapore-households-estimated-to-be-worlds-7thtop-overseas-travel-spenders-by-2025.html

WHO. (2002). Active Ageing: A Policy Framerwork. Second United Nations World Assembly on Ageing. Geneva: World Health Organization.

WHO Department of Ageing and Life Course. (2017). 10 Priorities Towards a Decade of Healthy Ageing. Geneva: World Health Organization.

WHO. (2017). Global Strategy and Action Plan on Ageing \& Health. Global Strategy and Action Plan on Ageing \& Health. Geneva: World Health Organization. 
eTropic 19.2 (2020) Special Issue: Sustainable Tropical Urbanism

Yong, V., Saito, Y., \& Chan, A. (2010). Changes in the Prevalence of Mobility Limitations \& Mobile Life Expectancy of Older Adults in Singapore, 1995-2005. Journal of Aging and Health , 22 (1), 120-140. https://doi.org/10.1177/0898264309351932

Yusuf, S., \& Nabeshima, K. (2012). Some Small Countries Do It Better : Rapid Growth and Its Causes in Singapore, Finland, and Ireland. Herndon: World Bank Publications. https://doi.org/10.1596/978-0-8213-8846-4

\section{Figures}

Figure 1 Singapore Population Demographic Transition Charts for 1980, 2015 and 2050. Singapore aging population transition with atypical inverted-V or mushroomshape population diagram indicating two waves of aging population in 2015 and 2050. Adapted from "M850581 Singapore Residents Aged 25 Years \& Over By Highest Qualification Attained, Sex And Age Group" (Singapore Department of Statistics, 2018a).

Figure 2 Singapore Singles Population Age 50 and above. Increasing Singapore Singles Population by age group of age 50 years old \& above, between 2000 and 2018; single by choice, widowhood or both (Singapore Department of Statistics, 2018b).

Figure 3 Demand for HDB 1 or 2-Bedroom Housing in Singapore. Increasing Demand in Singapore Housing Development Board 1 or 2 Bedroom Low-occupancy Housing, by population of age 35 years old \& above (Singapore Department of Statistics, 2018b).

Figure 4 SELP Lifespan relative to Typical Aging Lifespan. Arbitrary timeline illustration depicting mobility expansion and increased longevity in SELP lifespan relative to a typical aging lifespan.

\section{Tables}

Table 1 Singapore Infocomm Usage by Households and Individuals Survey (IMDA, 2019)

Table 2 Daily Internet Usage Rate in Singapore in 2016, by age group (statista, 2016) 259

Table 3 Comparisons of Aspects of Living and Baseline Criteria in Urban Planning 
eTropic 19.2 (2020) Special Issue: Sustainable Tropical Urbanism

\section{Appendix A}

UN and WHO correlated goals:

- Goal \#1 End poverty by supporting Healthy Aging and economic growth through engagement and access to education or vocational training, re-skilling to maintain employability among the elderly.

- Goal \#2 End hunger and achieve food security and improved nutrition for older people.

- Goal \#3 Ensure healthy lives \& promote wellbeing for all at all ages.

- Goal \#4 Ensure inclusive and equitable quality education and promote lifelong learning for all.

- Goal \#5 Achieve gender equality and empower all women and girls.

- Goal \#9 Build resilient infrastructure, promote inclusive and sustainable industrialization, and foster innovation.

- Goal \#10 Reduce Inequality: overcoming inequities limiting access to older people.

- Goal \#11 Make cities and human settlements inclusive, safe, resilient, and sustainable

- Goal \#16 Promote peaceful and inclusive societies for sustainable development.

\section{Acknowledgements}

I would like to thank Dr Simona Azzali (Lecturer and Program Coordinator of the Master of Planning and Urban Design at James Cook University, Singapore) for her guidance in the development of this paper.

André Yew is a graduate of the Master of Planning \& Urban Design, James Cook University Singapore. He majored in disaster resilience and tropical urbanism. Prior to the pursuit of the degree in urban planning and design, he had worked internationally in the architecture design industry. He received his earlier Master of Fine Arts in architectural illumination and a Bachelor of Science in interior design from the United States. His professional and personal experience inspires him to approach topics in urbanism from the perspective of design development and project management, as well as through empathy towards humanity and the environment. His international exposure also inspires him to continuously seek holistic approaches towards sustainability. Currently, he is a member of a geoscience and environmental sustainability technology consultancy in Singapore. He is also a sessional lecturer in urban planning at James Cook University Singapore. 